\title{
Humidification Performance of Heat and Moisture Exchangers for Pediatric Use
}

\author{
Yusuke Chikata, ${ }^{1}$ Chihiro Sumida, ${ }^{2}$ Jun Oto, ${ }^{3}$ Hideaki Imanaka, ${ }^{4}$ and Masaji Nishimura ${ }^{3}$ \\ ${ }^{1}$ The University of Tokushima Graduate School, 3-18-15 Kuramoto-cho, Tokushima City, Tokushima 770-8503, Japan \\ ${ }^{2}$ Faculty of Medicine, The University of Tokushima, 3-18-15 Kuramoto-cho, Tokushima City, Tokushima 770-8503, Japan \\ ${ }^{3}$ Department of Emergency and Critical Care Medicine, The University of Tokushima Graduate School, 3-18-15 Kuramoto-cho, \\ Tokushima City, Tokushima 770-8503, Japan \\ ${ }^{4}$ Department of Emergency and Disaster Medicine, Tokushima University Hospital, 2-50-1, Kuramoto-cho, Tokushima City, \\ Tokushima 770-8503, Japan
}

Correspondence should be addressed to Jun Oto, joto@clin.med.tokushima-u.ac.jp

Received 5 July 2011; Revised 17 October 2011; Accepted 17 October 2011

Academic Editor: Peter J. Papadakos

Copyright ( 92012 Yusuke Chikata et al. This is an open access article distributed under the Creative Commons Attribution License, which permits unrestricted use, distribution, and reproduction in any medium, provided the original work is properly cited.

Background. While heat and moisture exchangers (HMEs) have been increasingly used for humidification during mechanical ventilation, the efficacy of pediatric HMEs has not yet been fully evaluated. Methods. We tested ten pediatric HMEs when mechanically ventilating a model lung at respiratory rates of 20 and 30 breaths/min and pressure control of 10,15, and $20 \mathrm{cmH} \mathrm{H}_{2} \mathrm{O}$. The expiratory gas passed through a heated humidifier. We created two rates of leakage: $3.2 \mathrm{~L} / \mathrm{min}$ (small) and $5.1 \mathrm{~L} / \mathrm{min}$ (large) when pressure was $10 \mathrm{cmH}_{2} \mathrm{O}$. We measured absolute humidity $(\mathrm{AH})$ at the Y-piece. Results. Without leakage, eight of ten HMEs maintained AH at more than $30 \mathrm{mg} / \mathrm{L}$. With the small leak, AH decreased below $30 \mathrm{mg} / \mathrm{L}$ ( 26.6 to $29.5 \mathrm{mg} / \mathrm{L}$ ), decreasing further $(19.7$ to $27.3 \mathrm{mg} / \mathrm{L})$ with the large leak. Respiratory rate and pressure control level did not affect AH values. Conclusions. Pediatric HMEs provide adequate humidification performance when leakage is absent.

\section{Introduction}

In spontaneous breathing subjects, inspiratory gases are heated and humidified in the nasal cavity and pharynx; by the time, they reach the second bronchial bifurcation, temperature reaches $37^{\circ} \mathrm{C}$, and absolute humidity reaches $(\mathrm{AH})$ $44 \mathrm{mg} / \mathrm{L}$ [1]. In mechanically ventilated patients, because artificial airways bypass this natural gas conditioning, administered gases require heating and humidification. Inadequate humidification induces inspissations of airway secretions, destruction of airway epithelium, and hypothermia [2]. The incidence of endotracheal tube occlusion was reported between $0.8 \%$ and $2.6 \%$ in pediatric patients $[3,4]$. The American Association for Respiratory Care (AARC) recommends that inspiratory gases should reach a temperature of more than $30^{\circ} \mathrm{C}$ and $\mathrm{AH}$ of more than $30 \mathrm{mg} / \mathrm{L}$ [2].

Heat and moisture exchangers (HMEs) and heated humidifiers (active humidification) are commonly employed to warm and humidify medical gases. While HMEs are widely used during the mechanical ventilation of adults [5], their performance varies depending on model [6] and is affected by location, tidal volume, and minute volume $[7,8]$. For pediatric patients, because HME adds significant dead space and airway resistance to the circuit, and because there is a high risk of inadequate humidification owing to leakage around the endotracheal tube (ETT), long-term use of HMEs is generally avoided. Few studies, however, have reported how ventilator settings and ETT leakage influence the humidification performance of HMEs used for pediatric patients.

Using a pediatric model lung, we carried out a bench study to evaluate the effects of ventilator settings and leakage volume on the humidification performance of pediatric HMEs.

\section{Materials and Methods}

Ten different models of HME were investigated (Table 1). All HMEs were designed for pediatric use, and not to be 
TABLE 1: Features of tested heat and humidifier exchangers.

\begin{tabular}{lllccccc}
\hline No. & Device & Manufacturer & $\begin{array}{c}\text { Recommended } \\
\text { tidal volume } \\
(\mathrm{mL})\end{array}$ & $\begin{array}{c}\text { Measured } \\
\text { resistance, } \\
\mathrm{cmH}_{2} \mathrm{O} / \mathrm{L} / \mathrm{s}\end{array}$ & $\begin{array}{c}\text { Resistance from } \\
\text { manufacturer's } \\
\text { data, } \mathrm{cmH}_{2} \mathrm{O} / \mathrm{L} / \mathrm{s}\end{array}$ & Type of HME & $\begin{array}{r}\text { Dead } \\
\text { space } \\
(\mathrm{mL})\end{array}$ \\
\hline$(1)$ & Hygroboy & Tyco Healthcare & $75-300$ & 5.7 & 4.2 & hygroscopic & 26 \\
$(2)$ & HCH 5701 & Vital signs & $100-1,200$ & 0.6 & 1.9 & hygroscopic & 30 \\
$(3)$ & Pharrma Mini & Pharma Systems & $50-900$ & 4.3 & 4.2 & hydrophobic & 28 \\
$(4)$ & HMEF Mini & GE Healthcare & $60-500$ & 3.5 & 3.0 & hygroscopic & 21 \\
$(5)$ & Servo Humidifier 161 & Maquet & $70-600$ & 1.6 & 1.2 & hygroscopic & 21 \\
$(6)$ & Clear-Therm Mini & Intersurgical & $75-200$ & 3.3 & 3.4 & mix & 28 \\
$(7)$ & Humid-Vent 1 & Hudson RCI & $50-600$ & 1.2 & 0.9 & hygroscopic & 10 \\
$(8)$ & Hygrovent Child & Medisize & $50-250$ & 13.6 & 6.0 & hygroscopic & 12 \\
$(9)$ & Thermovent 600 & Smiths Medical & $<600$ & 1.2 & 2.9 & hydrophobic & 12 \\
$(10)$ & Vent Aid SK300CP & Fuji Medical & $50-300$ & 8.1 & 6.0 & hygroscopic & 12 \\
\hline
\end{tabular}

recommended for use in adult patient. Using a pediatric model lung (TTL model 1601, Michigan Instruments, Grand Rapids, MI) and a heated humidifier (MR730, Fisher \& Paykel, Auckland, New Zealand), we simulated real-life ventilatory conditions (Figure 1). A ventilator (PuritanBennett 840: Covidien, Carlsbad, CA) delivered medical gases through each tested HME to the TTL bellows, the heated humidifier, a limb with the heating wire, and a one-way valve connector to avoid contamination with expired gases. The compliance of the TTL bellows was set at $0.01 \mathrm{~L} / \mathrm{cmH}_{2} \mathrm{O}$. By inserting connectors with calibrated holes, we created two levels of leakage: $3.2 \mathrm{~L} / \mathrm{min}$ (small) and $5.1 \mathrm{~L} / \mathrm{min}$ (large) under airway pressure of $10 \mathrm{cmH}_{2} \mathrm{O}$. Ventilatory settings were assist-control mode, respiratory rates of 20 and 30 breaths/min, pressure control of 10 , 15 , and $20 \mathrm{cmH}_{2} \mathrm{O}$, inspiratory time of $0.8 \mathrm{~s}$, positive endexpiratory pressure of $3 \mathrm{cmH}_{2} \mathrm{O}$, and $\mathrm{F}_{\mathrm{I}} \mathrm{O}_{2}$ of 0.21 . At the airway opening of the simulated respiratory system, we measured $\mathrm{AH}, \mathrm{RH}$, and temperature using a rapid response capacitance-type moisture sensor (Moiscope, Senko Medical, Tokyo, Japan) described previously [7, 9]. Ambient relative humidity $(\mathrm{RH})$ was maintained between $51 \%$ and $61 \%$, and ambient temperature at $23.8^{\circ} \mathrm{C}$ to $24.8^{\circ} \mathrm{C}$. The inspired gases were warmed to $36^{\circ} \mathrm{C}$ at the chamber outlet of the heated humidifier and to $37^{\circ} \mathrm{C}$ at the end of the limb. After confirming the values of $\mathrm{RH}$ and temperature had stabilized, we recorded the values for $5 \mathrm{~min}$. A stabilization of these values was defined as when the $\mathrm{RH}$ varied within $2 \%$ and the temperature varied within $0.3^{\circ} \mathrm{C}$ for $5 \mathrm{~min}$ described previously $[9,10]$. At each change of ventilator settings, before recording data, we allowed at least $10 \mathrm{~min}$ and confirmed stabilization. All signals from the hygrometer were led to an analog/digital converter and recorded at $50 \mathrm{~Hz} /$ channel on computer using data acquisition software (WINDAQ, Dataq Instruments, Akron, OH).

The resistance of all HMEs was measured with a pressure sensor (TP-603T, $\pm 50 \mathrm{cmH}_{2} \mathrm{O}$, Nihon-Koden, Tokyo, Japan) placed between a flow generator and the HMEs. Thirty liters of flow was created by the flow generator and measured with a pneumotachometer (model 4700, 0-160 L/min,

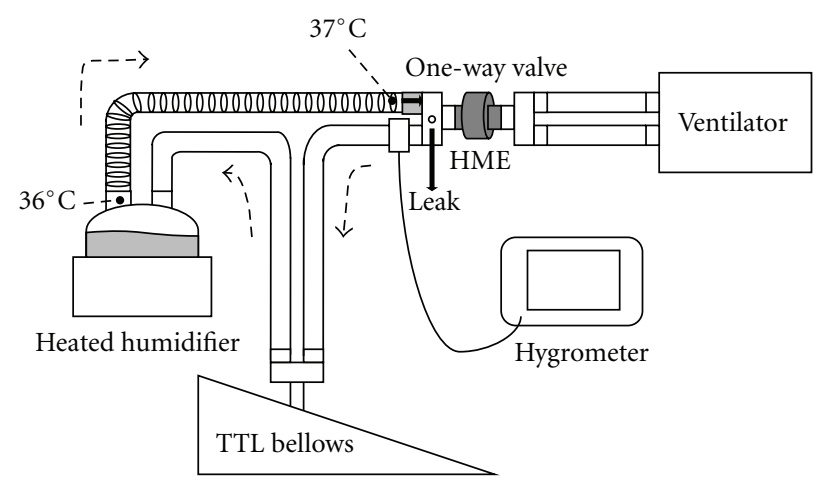

Figure 1: Experimental setup. In a circuit including a heated humidifier, a limb with a heating wire, and a one-way valve connector, a ventilator delivered medical gases, through the HME being tested, to the bellows. The gases were warmed to $36^{\circ} \mathrm{C}$ at the chamber outlet of the heated humidifier and to $37^{\circ} \mathrm{C}$ at the end of the limb. Two levels of leakage were created: $3.2 \mathrm{~L} / \mathrm{min}$ (small) and $5.1 \mathrm{~L} / \mathrm{min}$ (large) at airway pressure of $10 \mathrm{cmH}_{2} \mathrm{O}$. HME: heat and moisture exchanger.

Hans-Rudolph Inc., Kansas City, MO, USA) connected to a differential pressure transducer (TP-602T, $\pm 5 \mathrm{cmH}_{2} \mathrm{O}$, Nihon-Koden, Tokyo, Japan). Flow and pressure signals were amplified, digitized, and recorded at $100 \mathrm{~Hz}$ per signal using data acquisition software (WINDAQ, Dataq Instruments, Akron, OH, USA).

Results are expressed as mean $\pm \mathrm{SD}$. Analysis of variance was performed using repeated measures ANOVA, and Scheffe's test was performed as a post hoc test for multiple comparison. For each pediatric HME we tested, we examined the relationship between dead space and obtained $\mathrm{AH}$ values. The relationship between variables was assessed using Spearman's rho (rs). We also calculated the AH delivered/dead space (volume of HME) as an index of humidification efficiency. Comparison between our measured data and manufacturer data for resistance was obtained by Wilcoxon signedrank test. All statistical tests were two sided, and a $P$ value $<0.05$ was considered statistically significant. All statistical 


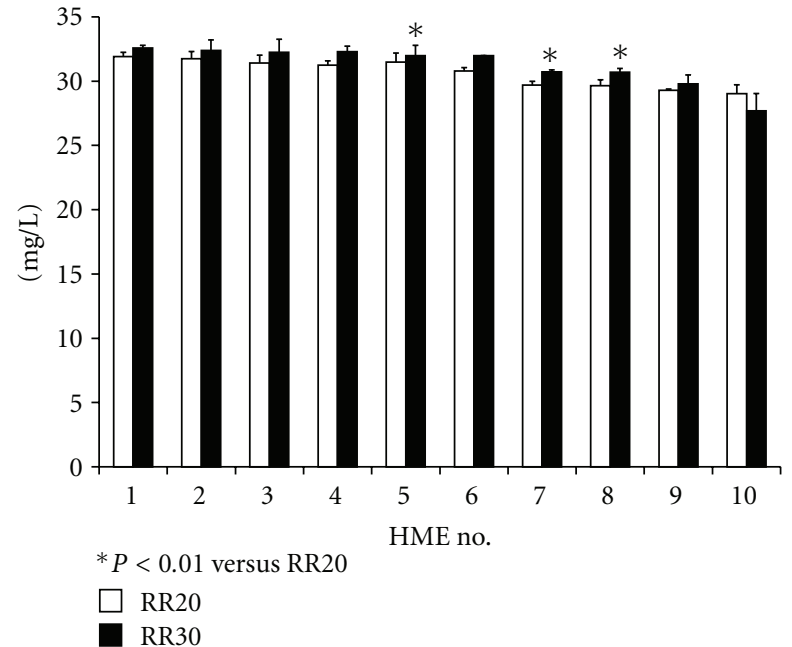

FIGURE 2: Effect of respiratory rate on absolute humidity in the absence of leakage. This figure shows the pooled results for pressure control settings of 10,15 , and $20 \mathrm{cmH}_{2} \mathrm{O}$ without leakage. With three HMEs, increasing the respiratory rate statistically significantly increased absolute humidity. Mean $\pm \mathrm{SD}$; ${ }^{*} P<0.01$ versus respiratory rate 20 breaths/min. HME: heat and moisture exchanger. RR: respiratory rate (breaths/min).

analysis was performed using commercial software (SPSS 11.01, SPSS, Chicago, IL).

\section{Results}

$\mathrm{AH}$ of expired gas at the end of the limb was about $36.5 \pm$ $0.6 \mathrm{mgH}_{2} \mathrm{O} / \mathrm{L}$, $\mathrm{RH}$ was $100 \%$, and temperature was $33.4 \pm$ $0.4^{\circ} \mathrm{C}$. Without leakage, recorded $\mathrm{AH}$ varied (28.4 to $32.4 \mathrm{mg} / \mathrm{L}$ ) among the tested HMEs, the average being $30.9 \pm$ $1.5 \mathrm{mg} / \mathrm{L}$. Eight of the ten HMEs maintained AH at more than $30 \mathrm{mg} / \mathrm{L}$. The levels of pressure control (tidal volume) did not statistically significantly affect $\mathrm{AH}$ (data are not shown). As the respiratory rate increased, $\mathrm{AH}$ increased in three HMEs, but the percentage difference between respiratory settings of 20 and 30 breaths/min always remained less than 3\%; changes in $\mathrm{AH}$ values with the other seven HMEs were negligible (Figure 2). With the small leak, $21.8 \% \pm$ $5.6 \%$ of tidal volume was lost, and with the large leak, $44.2 \% \pm 10.3 \%$. When there was leakage in the circuit, none of the HMEs were able to maintain AH above $30 \mathrm{mg} / \mathrm{L}$. With greater leakage, AH decreased with all HMEs (Figure 3). When the leak was small, AH was $28.6 \pm 1.3 \mathrm{mg} / \mathrm{L}$ ( 26.6 to $29.5 \mathrm{mg} / \mathrm{L}$ ), a $7.5 \%$ loss ( $92.5 \%$ of AH without leakage). With the large leak, AH dropped by $22 \%$ to $24.4 \pm 3.2 \mathrm{mg} / \mathrm{L}$ ( 19.7 to $27.3 \mathrm{mg} / \mathrm{L})(78 \%$ of AH without leakage). The mean ratio of AH to dead space among ten HMEs was $1.8 \pm 0.7$ (range: 1.1-3.0). There was a significant correlation between dead space of HME and AH values ( $\mathrm{rs}=0.85, P=0.018$ ) (Figure 4).

The average resistance of $10 \mathrm{HMEs}$ was $4.3 \pm 4.0 \mathrm{cmH}_{2} \mathrm{O} /$ $\mathrm{L} / \mathrm{s}$, with a maximum of $13.6 \mathrm{cmH}_{2} \mathrm{O} / \mathrm{L} / \mathrm{s}$ and a minimum of $0.6 \mathrm{cmH}_{2} \mathrm{O} / \mathrm{L} / \mathrm{s}$. The mean difference between our values and

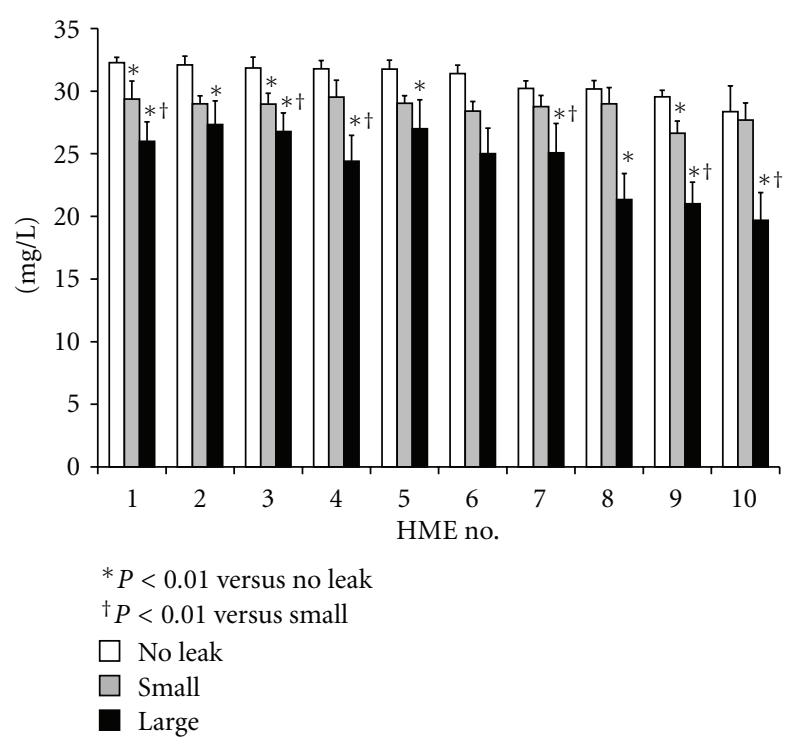

Figure 3: Effect of leakage on absolute humidity. This figure shows the pooled results for respiratory rates of 20 and 30 breaths $/ \mathrm{min}$, and with pressure control set at 10,15 , and $20 \mathrm{cmH}_{2} \mathrm{O}$. HME: heat and moisture exchanger. Mean $\pm \mathrm{SD} ;{ }^{*} P<0.01$ versus no leakage; ${ }^{\dagger} P<0.01$ versus small leak.

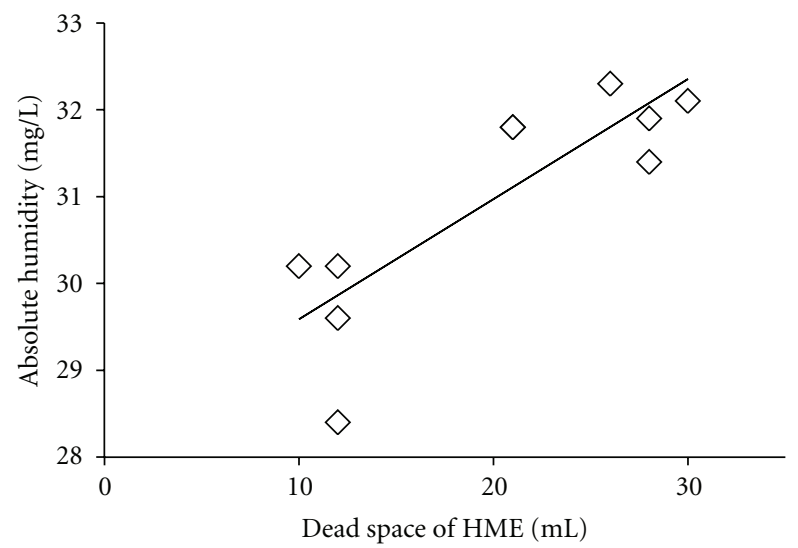

FIGURE 4: Relationship between absolute humidity and dead space in each HME. There was a statistically significant correlation between HME dead space and AH values ( $\mathrm{rs}=0.85, P=0.018)$. HME: heat and moisture exchanger.

those of the manufacturers' reports was $-1.0 \pm 2.6 \mathrm{cmH}_{2} \mathrm{O}$ / $\mathrm{L} / \mathrm{s}(P=0.27)$. Values were summarized in Table 1 .

\section{Discussion}

We investigated the effects of leakage volume and ventilatory settings on humidification performance in ten HMEs for pediatric use. Without leakage, eight of the ten pediatric HMEs performed within the AARC guideline recommendation $(\mathrm{AH} \min , 30 \mathrm{mg} / \mathrm{L})$. When there was leakage, whether large or small, AH decreased below $30 \mathrm{mg} / \mathrm{L}$ in all pediatric HMEs. 
After investigating adult HMEs and antibacterial filters, Lellouche et al. found that 18 of $48(38 \%)$ units were able to maintain $\mathrm{AH}$ at $30 \mathrm{mg} / \mathrm{L}$ or more, and the highest level of $\mathrm{AH}$ attained $31.9 \mathrm{mg} / \mathrm{L}$ [6]. There have been few reports, however, on the humidification performance of HMEs for pediatric use. Meanwhile, after investigating humidification with neonate patients, Fassassi et al. reported that use of an HME provided less AH $(32.4 \pm 2.8 \mathrm{mg} / \mathrm{L})$ than a heated humidifier [11]; Schiffmann et al. reported that both HMEs $(34 \pm 2.6 \mathrm{mg} / \mathrm{L})$ and heated humidifiers $(33.8 \pm 2.9 \mathrm{mg} / \mathrm{L})$ provided enough $\mathrm{AH}$ in mechanically ventilated neonates and infants to meet the AARC guideline recommendation [12]. In these reports, however, because the protocol measured humidity between the tracheal tubes and humidifying device, it is likely that contamination with fully humidified expiratory gas increased the recorded $\mathrm{AH}$ values. This conjecture is supported by the findings of Luchetti et al., who showed inspiratory gas temperatures below $30^{\circ} \mathrm{C}$ and $\mathrm{AH}$ of less than $28 \mathrm{mg} / \mathrm{L}$ in all HMEs used with pediatric patients $(3-33 \mathrm{~kg})$ [13]. In our study, to accurately measure inspiratory gas humidity, as in the Luchetti et al. study, we inserted a one-way valve to prevent the mingling of inspiratory and expiratory gases.

The HMEs we tested were able to maintain $\mathrm{AH}$ at a level in the range from 28.4 to $32.4 \mathrm{mg} / \mathrm{L}$. AH ranging from 30 to $25 \mathrm{mg} / \mathrm{L}$ is usually considered reluctantly acceptable but not desirable, while $\mathrm{AH}$ of less than $25 \mathrm{mg} / \mathrm{L}$ exceeds threshold and should be avoided during mechanical ventilation [6]. With a large leak in the circuit, $\mathrm{AH}$ fell below $25 \mathrm{mg} / \mathrm{L}$ in five of the ten pediatric HMEs we tested.

Comparing manufacturer data with actual performance, Lellouche et al. have reported that different HMEs have different performance, some performing so poorly that they should not be used [6]. While the reasons for differences were not clear in the ten units we tested, we did observe a tendency for HMEs with less dead space to provide less $\mathrm{AH}$ (Figure 4). It may be that the extra internal volume of HMEs with more dead space is related to the ability to maintain higher levels of humidity. When the respiratory rate increased, the AH increased with three HMEs and did not change with the remaining seven devices. When, from $10 \mathrm{cmH}_{2} \mathrm{O}$, the pressure control setting was increased to $20 \mathrm{cmH}_{2} \mathrm{O}, \mathrm{AH}$ tended to fall by approximately $3 \%$ although this decrease was not statistically significant. HMEs with little dead space may struggle to humidify gases flowing in large tidal volumes. Lucato et al. have reported that HMEs were more efficient when used with low tidal volume ventilation [8].

For mechanically ventilated adults with humidification provided with an HME, when air leakage increases, inspiratory gas humidification decreases $[14,15]$. Consequently, AARC guidelines recommend not using an HME when leakage volume exceeds $30 \%$ of inspiratory tidal volume [2]. However, the humidification performance of pediatric HMEs has not been clarified. Luchetti et al. reported that AH was less than $30 \mathrm{mg} / \mathrm{L}$ when HMEs were used for pediatric patients with uncuffed ETTs [13]. Schiffmann et al. has also suggested, for neonate and pediatric patients, that HME humidification performance decreases when leakage volume exceeds 15\% [12]. The relationship between leakage volumes and $\mathrm{AH}$, however, has not been examined. As far as we know, this is the first report to evaluate, for pediatric patients, the effect of leakage volume on AH in inspiratory gas. Although, in the absence of leakage, most of the HMEs we tested could maintain $\mathrm{AH}$ at more than $30 \mathrm{mg} / \mathrm{L}$, we found that when there was leakage, with all HMEs, AH decreased below $30 \mathrm{mg} / \mathrm{L}$ (Figure 3).

This study has several limitations. Naturally, because it is based on a model-lung simulation, the findings do not directly correspond to clinical situations. Moreover, our observation period was relatively short; the performance and safety of HMEs in prolonged mechanical ventilation remain to be proven. We simulated real-life ventilatory conditions using $\mathrm{HH}$ and $\mathrm{AH}$ of expired gas which were slightly higher than those of previous study [6]. This might lead to overestimation of inspired gas humidity in the present study.

In conclusion, without respiratory circuit leakage, the majority of the HMEs for pediatric use provided sufficient humidification. With leakage, however, humidification decreased and was not maintained at guideline values. If there is leakage around the tracheal tube, extra caution is advised when using an HME for humidification for pediatric patients.

\section{Financial Support}

It was a departmental funding.

\section{Conflict of Interests}

None of the authors have any conflict of interests to declare in relation to this paper.

\section{References}

[1] E. R. McFadden, B. M. Pichurko, and H. F. Bowman, "Thermal mapping of the airways in humans," Journal of Applied Physiology, vol. 58, no. 2, pp. 564-570, 1985.

[2] R. Branson, R. S. Campbell, R. L. Chatburn et al., "AARC clinical practice guideline: humidification during mechanical ventilation,” Respiratory Care, vol. 37, pp. 887-890, 1992.

[3] R. Rivera and J. Tibballs, "Complications of endotracheal intubation and mechanical ventilation in infants and children," Critical Care Medicine, vol. 20, no. 2, pp. 193-199, 1992.

[4] A. E. Black, D. J. Hatch, and N. Nauth-Misir, "Complications of nasotracheal intubation in neonates, infants and children: a review of 4 years' experience in a children's hospital," British Journal of Anaesthesia, vol. 65, no. 4, pp. 461-467, 1990.

[5] R. D. Branson, "Humidification for patients with artificial airways," Respiratory Care, vol. 44, no. 6, pp. 630-641, 1999.

[6] F. Lellouche, S. Taillé, F. Lefrançois et al., "Humidification performance of 48 passive airway humidifiers comparison with manufacturer data," Chest, vol. 135, no. 2, pp. 276-286, 2009.

[7] D. Inui, J. Oto, and M. Nishimura, "Effect of heat and moisture exchanger (HME) positioning on inspiratory gas humidification," BMC Pulmonary Medicine, vol. 6, article 19, 2006.

[8] J. J. J. Lucato, A. B. Adams, R. Souza, J. A. Torquato, C. R. R. Carvalho, and J. J. Marini, "Evaluating humidity recovery efficiency of currently available heat and moisture exchangers: 
a respiratory system model study," Clinics, vol. 64, no. 6, pp. 585-590, 2009.

[9] J. Oto, H. Imanaka, and M. Nishimura, "Clinical factors affecting inspired gas humidification and oral dryness during noninvasive ventilation," Journal of Critical Care, vol. 26, no. 5, pp. 535.e9-535.e15, 2011.

[10] A. E. Holland, L. Denehy, C. A. Buchan, and J. W. Wilson, "Efficacy of a heated passover humidifier during noninvasive ventilation: a bench study," Respiratory Care, vol. 52, no. 1, pp. 38-44, 2007.

[11] M. Fassassi, F. Michel, L. Thomachot et al., "Airway humidification with a heat and moisture exchanger in mechanically ventilated neonates: a preliminary evaluation," Intensive Care Medicine, vol. 33, no. 2, pp. 336-343, 2007.

[12] H. Schiffmann, J. Rathgeber, D. Singer et al., "Airway humidification in mechanically ventilated neonates and infants: a comparative study of a heat and moisture exchanger vs. a heated humidifier using a new fast-response capacitive humidity sensor," Critical Care Medicine, vol. 25, no. 10, pp. 17551760, 1997.

[13] M. Luchetti, A. Pigna, A. Gentili et al., "Evaluation of the effiency of heat and moisture exchangers during pediatric anaesthesia," Paediatric Anaesthesia, vol. 9, pp. 39-45, 1999.

[14] S. E. Tilling and B. Hayes, "Heat and Moisture Exchangers in artificial ventilation. An experimental study of the effect of gas leakage," British Journal of Anaesthesia, vol. 59, no. 9, pp. 1181$1188,1987$.

[15] F. Lellouche, S. M. Maggiore, A. Lyazidi et al., "Water content of delivered gases during non-invasive ventilation in healthy subjects," Intensive Care Medicine, vol. 35, no. 6, pp. 987-995, 2009. 


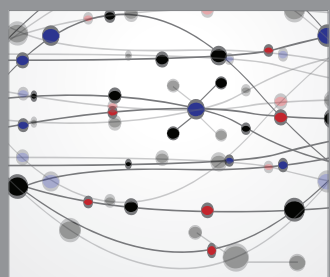

The Scientific World Journal
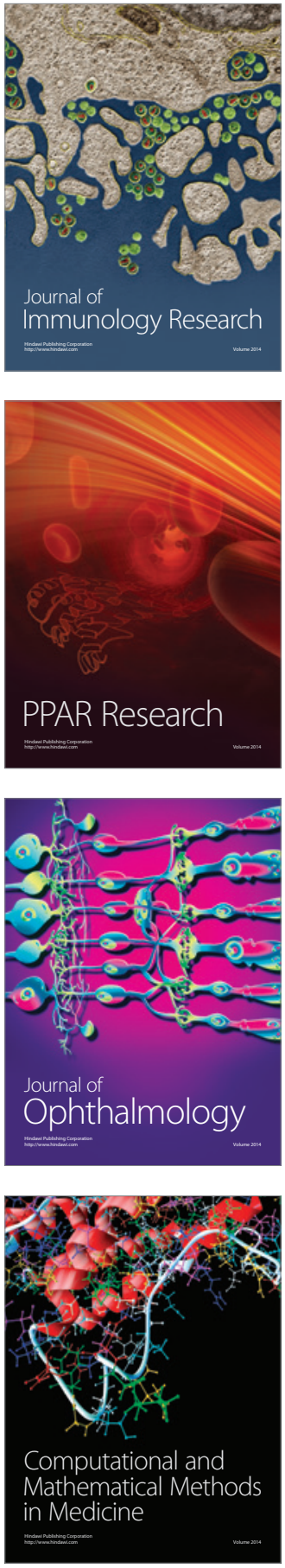

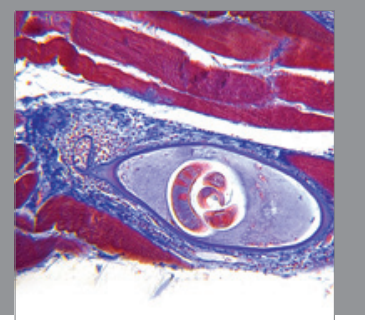

Gastroenterology

Research and Practice
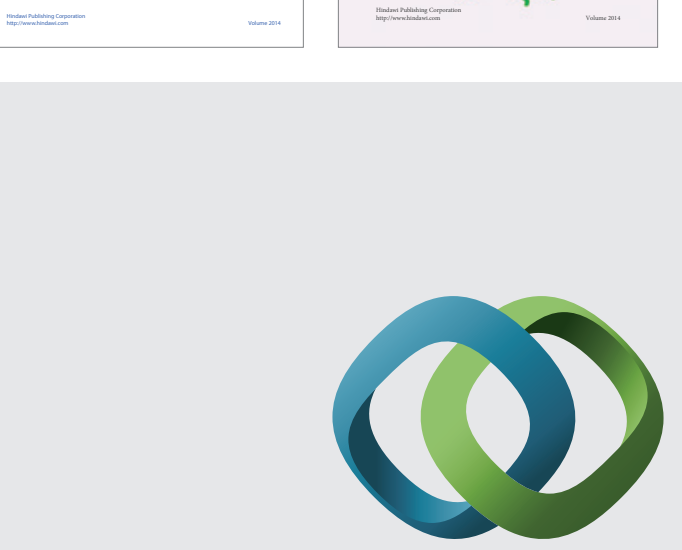

\section{Hindawi}

Submit your manuscripts at

http://www.hindawi.com
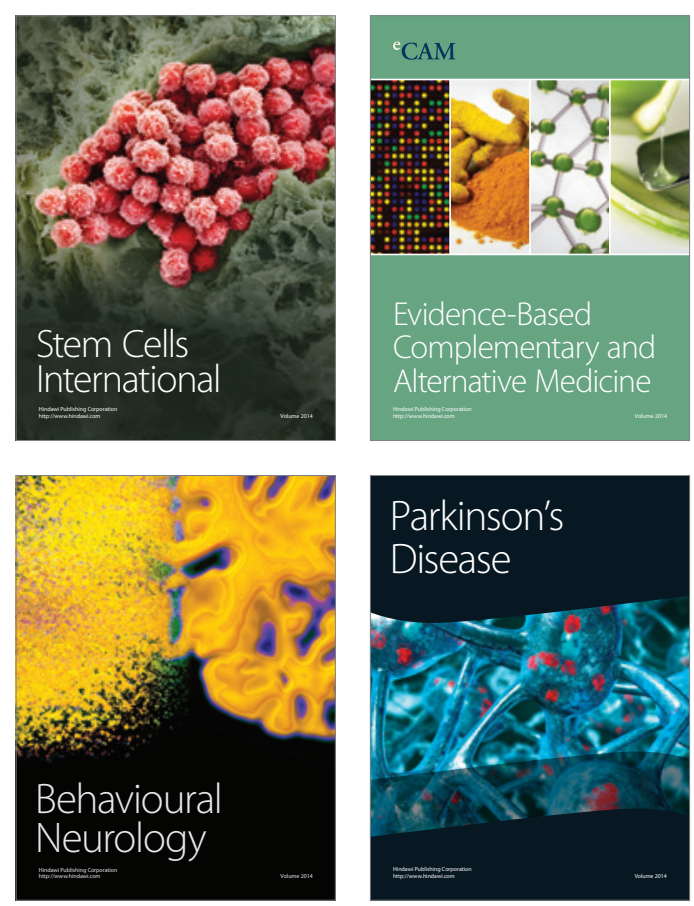

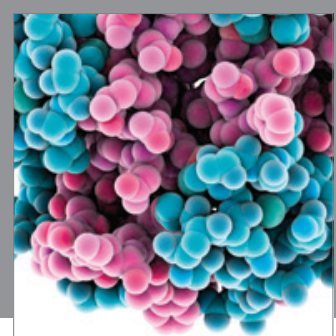

Journal of
Diabetes Research

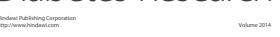

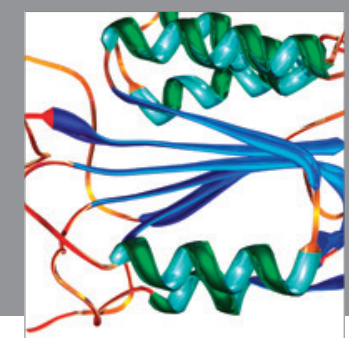

Disease Markers
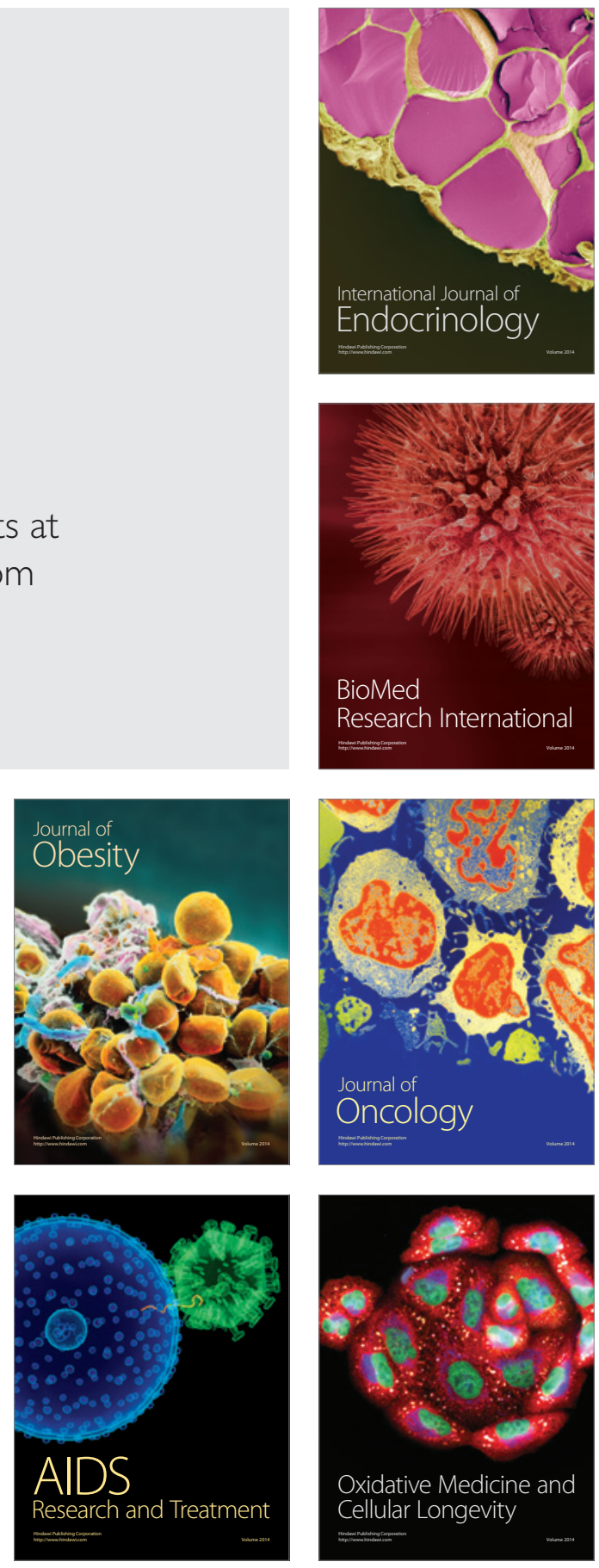